\title{
Von der Liebe und vom Abschiednehmen
}

\author{
Erhard Taverna
}

Unterschiedlicher könnten die Werke kaum sein, und doch handeln sie alle von Zuneigung und Abschiednehmen. Der Psychiater Ada-Jens Koemeda berichtet von einem Dreieck der Liebe, dem der Mann abhanden kommt, der Neurologe Claude-André Dessibourg (alias Luezior) nimmt Abschied von seiner Mutter, und die Pflegefachfrau Elisabeth Wenger protokolliert Gespräche mit Angehörigen von Krebskranken.

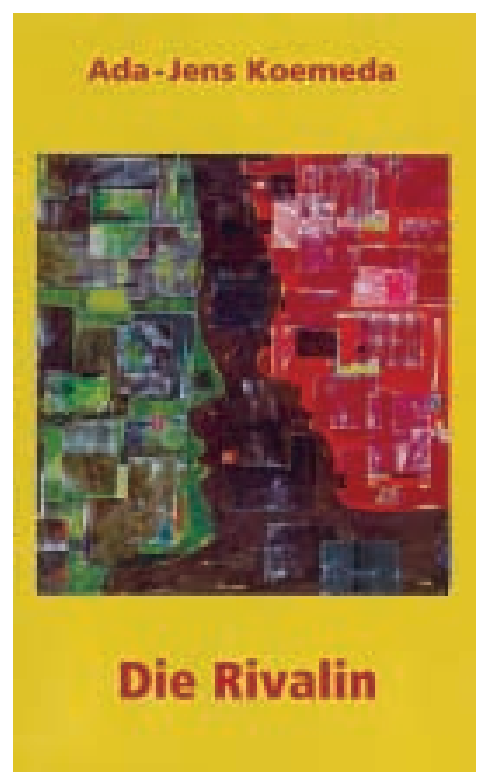

«Die Rivalin»

Was Mann und Frau ausserhalb der Ehe herumtreibt, fasziniert die Literatur seit eh und je. Jüngste Beispiele sind Markus Werners «Am Hang» und Wilhelm Genazinos «Die Liebesblödigkeit». Ada-Jens Koemeda, Arzt und Familientherapeut mit Praxis in Zürich, folgt dieser Tradition. Als Prager sudetendeutscher Abstammung hat er im Unterschied zu seinen ersten Büchern eine Novelle in deutscher Sprache verfasst. Ein Bergunfall beendet eine Ehe und eine Liebschaft. Zwei Frauen berichten in einem Briefwechsel von den ersten Wochen und Monaten nach dem Begräbnis. Helen, die Lektorin und heimliche Liebe des Verstorbenen, nähert sich, ohne die Wahrheit aufzudecken, der Witwe Melanie, die sich misstrauisch und neugierig auf eine Begegnung einlässt. Trauer und Eifersucht schaffen eine Verbindung, die fast zur Freund- schaft wird, bis die Legale der Illegalen auf die Schliche kommt. In einer furiosen Anklagerede wird abgerechnet. Dass die eine Schweizerin ist und die andere, wie der Verstorbene, aus Polen stammt, gerät der wütenden Betrogenen zur pauschalen Verurteilung einer ganzen Gesellschaft: «Und siehst Du, Helen, das ist nun den Kommunisten gelungen ... bei euch in Polen, in Russland, in Ungarn, überall: die Psychopathisierung, nicht von einzelnen Menschen, nein, von ganzen Nationen! Nicht einmal Dschingis Khan hatte das geschafft, nicht einmal Hitler. Ja, tragisch!» Die gewählte Erzähltechnik zweier Briefmonologe, gleichsam Rücken an Rücken, schafft eine fast klinische Distanz. Die Rivalinnen sind subtil beschrieben, äusserlich und innerlich. Dabei ist ein Kammerspiel entstanden, eine Fallgeschichte, ein Psychodrama mit einem überraschenden Ende. Der deutsche Schriftsteller Martin Walser zu diesem Roman: «Die deutsche Sprache kann froh sein über so kräftigen Zuzug.»

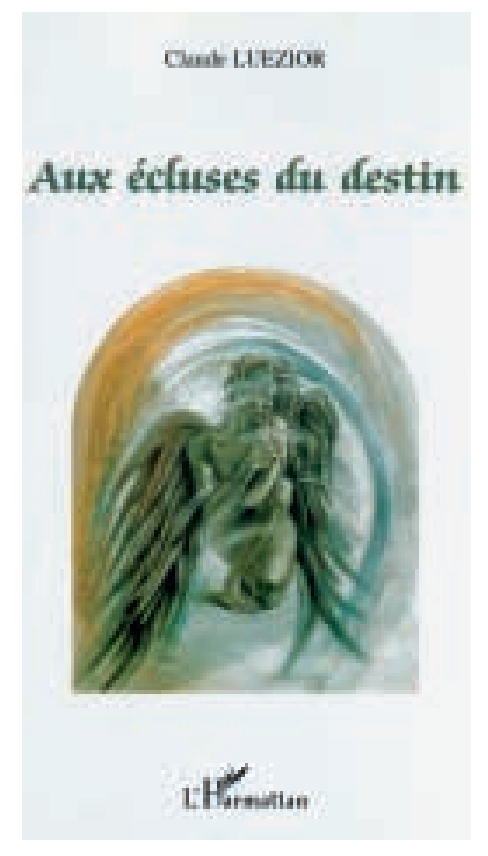

\section{«Aux écluses du destin»}

Das jüngste Werk des früheren CHUV-Chefarztes Claude-André Dessibourg handelt vom Sterben seiner Mutter. Mit einfachen Worten, in einer 
poetischen, sentenzhaften Sprache beschreibt er seinen Abschied von einem geliebten Menschen: «Austères nuances du souffle qui s'épuise. Pourquoi faut il tant d'oxygène au bûcher qui s'éteint?» Dem Autor gelingen immer wieder einprägsame Formulierungen, bei denen es sich zu verweilen lohnt: «C'est l'exigeante ferveur de l'existence: il faut coûte que coûte boire à satiété le limon de la sénescence.» Die Bitterkeit der letzten Lebenstage wird nicht beschönigt, sie werden zum Gleichnis, zur behutsamen und zerbrechlichen Annäherung an ein letztlich unfassbares Ereignis. Revolte und Mitgefühl sind typisch für seine filigranen Texte, die immer den Schmerz durch die Liebe zu überwinden suchen. Seine bisher über zwanzig publizierten Werke haben ihm in Frankreich zahlreiche Preise eingetragen. Einige davon sind in deutschen, rumänischen, griechischen und italienischen Übersetzungen erhältlich.

\section{«... und falls dir Krebs Angst macht ...»}

Eine Annäherung ohne Scheu und Pflichtgefühl nennt die Autorin Elisabeth Wenger ihr dreiteiliges Buch, das zuerst brieflich und mit E-Mails vom Sterben des Ehemannes und Wissenschaftsjournalisten Wenger erzählt. Im zweiten Teil sind fünfzehn Gesprächsprotokolle von Angehörigen zusammengefasst, und der dritte Teil enthält Fachbeiträge aus palliativer und psychoonkologischer Sicht. «Es soll kein Tränendrüsenbuch sein», sagt die Fachfrau, «es geht der Frage nach, wie es weitergeht, wenn die aufwendigen Therapien keine Wirkung mehr zeigen.» Das Buch erzählt in ihren eigenen Worten Geschichten über Hoffnungen und Enttäuschungen, über Angst und Tapferkeit, über Herzlosigkeit und Hilfsbereitschaft, über Verzweiflung und Liebe. Ein klug und einfühlend geschriebener Bericht, der die eigene Lebenserfahrung und das berufliche Können eindrücklich zusammenbringt. Sehr schön und passend zum Inhalt sind die schwarzweissen Bilder des mehrfach ausgezeichneten Berner Fotografen Hansueli Trachsel.

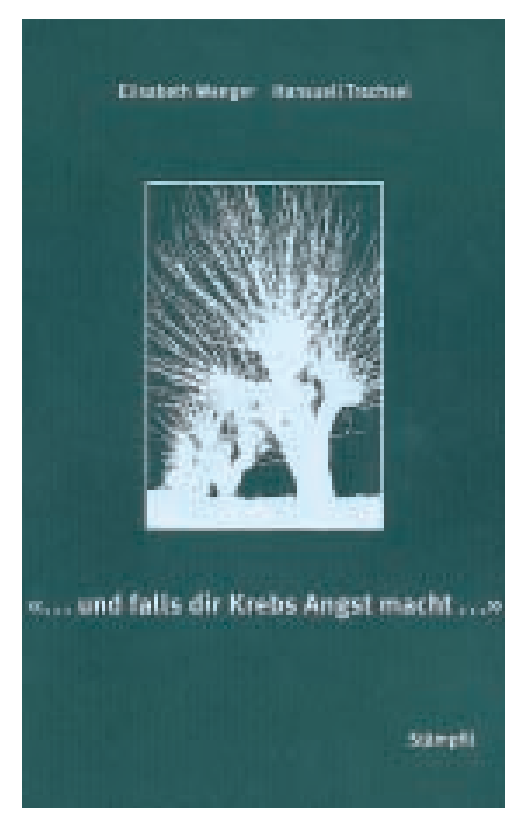

- Ada-Jens Koemeda. Die Rivalin. Gutach/D: Drey-Verlag; 2004. 164 Seiten.

- Claude Luezior. Aux écluses du destin. Paris: L'Harmattan; 2004. 95 Seiten.

- Elisabeth Wenger. «... und falls dir Krebs Angst macht ...» Bern: Stämpfli Verlag; 2004. 199 Seiten. 